\title{
RESEARCH
}

\section{COURSE OF ACUTE PANCREATITIS IN THE ELDERLY EVALUATED WITH COMPUTED TOMOGRAPHY SCAN}

Turkish Journal of Geriatrics

DOI: 10.31086/tigeri.2020.169

2020; 23(3): 326-333

\section{n Şevki KONUR ${ }^{1}$ iD \\ - Neslihan SÜRMELi² (D) \\ - Ihsan GÜNDÜZ3 ${ }^{3}$ D \\ - Ümit Haluk ILIKLERDEN ${ }^{4}$ (D) \\ - Ramazan DERTLi ${ }^{5}$ (D) \\ - Yusuf KAYAR ${ }^{5}$ D}

\section{CORRESPONDANCE}

\section{Yusuf KAYAR}

Saglik Bilimleri University, Van Education and

Research Hospital, Department of Internal

Medicine, Division of Gastroenterology, Van, Turkey

Phone: +904322531700

e-mail: ykayar@yahoo.com

Received: Apr 28, 2020

Accepted: Jul 27, 2020

Saglik Bilimleri University, Van Education and Research Hospital, Department of Internal Medicine, Van, Turkey

2 Van Yuzuncu Yil University, Health High School, Nutrition and Diets Unit, Van, Turkey

Saglik Bilimleri University, Van Education and Research Hospital, Department of Surgery, Division of Gastroenterology, Van, Turkey

${ }^{4}$ Van Yuzuncu Yil University, Department of Surgery, Van, Turkey

${ }^{5}$ Saglik Bilimleri University, Van Education and Research Hospital, Department of Internal Medicine, Division of Gastroenterology, Van, Turkey

\section{Abstract}

Introduction: In our study, we aimed to evaluate how age affects the severity and course of acute pancreatitis according to the modified Balthazar scoring system.

Materials and methods: 354 patients diagnosed with acute-pancreatitis and followed-up in our hospital between July/2013-February/2019 were included our study. Demographic data, comorbid diseases and mortality rates of all patients were documented. Patients with aged 65 and over were assessed as geriatric population. All patients included in the study underwent contrast enhanced abdominal computed-tomography within the first 12 hours and on days 3 to 7 . According to the modified Balthazar score, patients with mild, moderate and severe acutepancreatitis respectively. The relationship between age and computed-tomography findings was analyzed.

Results: 206 (58.2\%) of the patients included in the study were women. Mean age was $54.8 \pm 17.9$ years (18-100 years). Geriatric population consisted of $129(36.5 \%)$ patients. There was no statistically significant difference between the two groups according to the modified Balthazar classification on the initial computedtomographies on admission ( $p>0.05)$. However, on computed-tomography scans taken after the third day, severe acute-pancreatitis was detected significantly more frequently in the elderly $(p<0.05)$. Additionally, in comparing the disease progression on computed-tomography scans, disease progression was significantly higher in the elderly group $(p<0.05)$. In addition, comorbidity score and mortality rate were found to be significantly higher in the elderly group ( $p<0.001, p: 0042$, respectively).

Conclusion: In acute pancreatitis, age may have an effect on the severity of the disease. For this reason, multidisciplinary approach and close follow-up with monitoring is crucial in geriatric patients.

Keywords: Aged; Tomography, X-Ray computed; Pancreatitis 


\section{INTRODUCTION}

Acute pancreatitis (AP) is an acute inflammatory disease of the pancreas and peripancreatic tissues (1). The incidence in western countries has increased steadily in recent year $(2,3)$. AP is a potentially fatal disease with a general mortality rate between $2.1 \%$ and $7.8 \%$ which may increase up to $10 \%-23 \%$ if pancreatic necrosis develops $(2,3)$. Mortality associated with AP occurs most frequently for two reasons. While early mortality occurs due to severe and irreversible multiorgan dysfunction, late mortality results from pancreatitis induced sepsis followed by organ failure (4).

Due to the increasing life span, elderly patients constitute a large portion of the population. Largescale cohort studies show that, the group with the highest rate of hospitalization due to $A P$ is the elderly population (5). In cases of $A P$, it is of great importance to identify the disease and determine its severity in the early stages $(6,7)$. In this context, besides many criteria in determining the severity of AP age is used as a factor. Age $>55$ is used as a criterion in both Glasgow scoring system and Ranson scoring system $(8,9)$. Age is also included as a parameter in the Acute Physiology and Chronic Health Assessment (APACHE) score (10). All these scoring systems are used to differentiate mild acute pancreatitis from severe acute pancreatitis at an early stage (11).

Studies dealing with the relationship between age and prognosis show conflicting results and the relationship between AP severity and age is still controversial (12). In some studies, the mortality rate in elderly patients was similar to that in other age groups (13). In the study of Losurdo et al. evaluating patients over the age of 70 with acute biliary pancreatitis, despite high comorbidity rates in elderly group, mortality and disease severity were similar to those of younger patients (14). In contrast, in another study, which investigated the relationship between age, course of disease and mortality, it was shown that the disease was more severe in the elderly and the overall mortality rate increased from $2 \%$ in those under 55 years to $11 \%$ in older patients (15).

The physiology and morphology of organs change with age, which is a natural process. Therefore, the response of metabolism to external factors and diseases also varies. In conjunction with the aging of our population, it is important to clarify the impact of AP in the elderly in order to identify and manage therapeutic strategies. In this study, we aimed to evaluate the severity and course of acute pancreatitis in elderly patients according to the modified Balthazar scoring system.

\section{MATERIAL AND METHOD}

\section{Study design}

354 patients with acute pancreatitis followed up in our hospital, gastroenterology service between July 2013 and February 2019 were included our study, The diagnosis of AP was based on the American College of Gastroenterology guidelines (16). Patients with chronic pancreatitis or with contrast agent allergies, pregnant women, and those who did not want to participate in the study were excluded from the study. Demographic data (age, gender) of all patients were documented. Two separate groups were formed according to the age of the patients. Those aged 65 and over were assessed as geriatric population. AP etiology was determined in all patients. Etiologies were classified as biliary, alcohol induced, drug/ toxin induced, hyperlipidemia, post-endoscopic retrograde cholangiopancreatography (ERCP), infectious, malignancy related, hypercalcemia, genetic and structural anomalies. Those with no underlying pathology were evaluated as idiopathic AP. Comorbid diseases were documented in patients with AP. Charlson comorbidity index $(\mathrm{CCl})$ was calculated according to the existing comorbidities (17). The two groups (non-elderly and elderly groups) were compared in terms of demographic futures, presence of diabetes mellitus, $\mathrm{CCl}$ score and mortality. 


\section{Severity of acute pancreatitis}

All patients included in the study underwent contrast abdominal computed tomography (CT) within the first 12 hours and on days 3 to 7 . Besides pancreatic necrosis and peripancreatic collection; extrapancreatic findings like ascites, pleural effusion, extrapancreatic parenchymal abnormalities (subcapsular effusion, hemorrhage or infarction), gastrointestinal tract involvement (inflammation, intramural hematoma orperforation) and vascular complications (arterial hemorrhage, venous thrombosis or pseudo-aneurysm) were evaluated. AP was evaluated according to the modified Balthazar classification. According to this scoring, patients with scores of $0-2,4-6$ and $8-10$ were evaluated as mild, moderate and severe $A P$, respectively (18).

\section{Ethics statement}

Ethics approval was obtained from the Ethics Committee of our hospital to carry out this study. All procedures were in accordance with the ethical standards of our institution's Human Experiment Committee and the Helsinki Declaration.

\section{Statistical Analysis}

The results were analyzed with "The Statistical Package for the Social Sciences 124.0 (SPSS Armonk, NY: IBM Corp.)". Continuous values were given as mean ( \pm standard deviation) and categorical data as frequency and percentage $(N, \%)$. Distribution was tested with the Kolmogorov-Simirnov test, histogram, and \pm SD. Non parametric data of the groups were compared using Mann - Whitney $U$ test and parametric data using Independet $T$ test. Chi-square test was used to test categorical data. Cases with $p<0.05$ were considered statistically significant.

\section{RESULTS}

Of 354 patients with AP, 206 (58.2\%) were women. Mean age was $54.8 \pm 17.9$ years (age range: 18100 years). The number of patients in the geriatric population ( $\geq 65$ years) was 129 (36.5\%). There was no significant difference between the geriatric and non-geriatric groups in terms of gender $(p>$ $0.05)$. The mean $\mathrm{CCl}$ was $1.67 \pm 1.04$ in all patients, $3.39 \pm 2.1$ in the elderly group, and $0,68 \pm 1.11$ in the non-elderly group. The presence of diabetes mellitus and mean $\mathrm{CCl}$ value were significantly higher in the elderly group $(p<0.001)$. Analysis of AP etiologies were as follows: While in 193 (54.5\%) cases etiology was biliary, in $50(14.1 \%)$ patients drug or toxic substance induced, in 28 (7.9\%) patients secondary to ERCP, in 10 (2.8\%) patients hyperlipidemia and in 8 (2.3\%) patients alcohol induced AP were observed. In 32 cases other causes (structural pathologies such as annular pancreas and pancreatic divisium, malignancy, hypercalcemia, etc.) were detected. In 33 (9.3\%) patients any cause could be detected (idiopathic AP). In terms of severity of AP according to modified Balthazar classification on initial tomographies in young and elderly group; there was no statistically significant difference between the groups ( $p>0.05)$. However, on the follow up imaging taken after the third day, severe AP ratio was significantly higher in the elderly $(p<0.05)$. In analysing the disease progress on the follow up imaging compared to initial CT scan results are classified as regression, progression or no-change. Disease progression was significantly higher in the elderly group $(p<0.05)$. Also the mortality rate was significantly higher in the elderly group 4 (3.1\%) and $1(0.4 \%)$ respectively, p:0.042) (Table 1).

Progress of AP severity in both groups was analyzed in detail. In the geriatric group; of 12 patients in stage A initially, 8 (66.6\%) patients remained as stage A, $2(16.7 \%)$ patients progressed to stage $B$ and $2(16.7 \%)$ patients progressed to stage $C$ on the follow up CT taken after 72 hours. Of 12 patients in stage B initially, 8 (66.7\%) patients remained as stage B on control CT scan, 4 (33.3\%) patients progressed to stage C. 72 patients were in stage C initially. 43 (59.7\%) of these patients remained as stage C, 11 (15.3\%) 
Table 1. Demographic characters and CT scores in Patient with Acute Pancreatitis

\begin{tabular}{|c|c|c|c|c|}
\hline & $\begin{array}{l}\text { Elderly patients } \\
\text { N:129 (36.5\%) }\end{array}$ & $\begin{array}{l}\text { Non-elderly patients } \\
\text { N:225 }(63.5 \%)\end{array}$ & \begin{tabular}{|l} 
Total \\
$\mathrm{N}: 354$
\end{tabular} & $P$ value \\
\hline Age (year) & $73.8 \pm 7.6$ & $43.8 \pm 11.9$ & $54.8 \pm 17.9$ & $<0.001^{\star \star}$ \\
\hline (Mean, SD, Range) & $(65-100)$ & $(18-65)$ & $(18-100)$ & \\
\hline Swex & & & & 0.114 \\
\hline Male & $61(47.3 \%)$ & 87 (38.7\%) & $148(41.8 \%)$ & \\
\hline Female & $68(52.7 \%)$ & $138(61.3 \%)$ & $206(58.2 \%)$ & \\
\hline Diabetes Mellitus & & & & $<0.001^{*}$ \\
\hline Yes & $38(29.5 \%)$ & $25(11.1 \%)$ & $63(17.8 \%)$ & \\
\hline None & $91(70.5 \%)$ & $200(88.9 \%)$ & 291 (82.2\%) & \\
\hline Charlson comorbidity index score & $3.39 \pm 2.1$ & $0,68 \pm 1.11$ & $1.67 \pm 1.04$ & $<0.001 *$ \\
\hline $\begin{array}{l}\text { Balthazar classification } \\
\text { (On admission) }\end{array}$ & & & & 0.245 \\
\hline Mild & $96(\% 74.4)$ & $152(\% 68.9)$ & $251(\% 70.9)$ & \\
\hline Moderate & $31(\% 24.0)$ & $69(\% 30.7)$ & $100(\% 28.2)$ & \\
\hline Severe & $2(\% 1.6)$ & $1(\% 0.4)$ & $3(\% 0.9)$ & \\
\hline $\begin{array}{l}\text { Balthazar classification } \\
\text { (After } 72 \text { hours) }\end{array}$ & & & & $0.048^{\star}$ \\
\hline Mild & $86(\% 66.7)$ & $170(\% 75.6)$ & $256(\% 72.3)$ & 0.072 \\
\hline Moderate & $31(\% 24.0)$ & 47 (\%20.9) & 78 (\%22.1) & 0.492 \\
\hline Severe & 12 (\%9.3) & $8(\% 3.6)$ & 20 (\%5.6) & $0.024^{*}$ \\
\hline CT changes & & & & $0.013^{*}$ \\
\hline Regression & $21(16,3 \%)$ & $56(24.9 \%)$ & 77 (21.8\%) & 0.059 \\
\hline Progression & $36(27.9 \%)$ & $36(16.0 \%)$ & 72 (20.3\%) & $0.007^{\star}$ \\
\hline No change & 72 (55.8\%) & $133(59.1 \%)$ & 205 (57.9\%) & 0.545 \\
\hline Mortality & & & & $.042^{\star}$ \\
\hline Yes & 4 (3.1\%) & $1(0.4 \%)$ & 5 (1.4\%) & \\
\hline None & $125(\% 96.9)$ & 224 (99.6\%) & 349 (98.6\%) & \\
\hline
\end{tabular}

$*: p<0.05,{ }^{* *}: p<0.001$

patients regressed to stage $A$ and $B$, and 18 (25.0\%) patients progressed to stage $D$ and $E$ on control CT scans. Of 14 patients in stage D, 2 (14.3\%) patients remained as stage $D, 7$ (50.0\%) patients regressed to stage $A, B, C$, and 5 (35.7\%) patients progressed to stage $E$. In stage $E$ initially, there were 19 patients. 17 (89.4\%) patients remained as stage $E$, and $2(10.6 \%)$ patients regressed to stage
A to $D$ on the control CT scan (Table 2).

In the non-geriatric group; there were 50 patients in stage A on initial imaging, of these 40 (80\%) remained as stage $A$ and 10 (20\%) progressed to stage $B, C$ and $D$ on control tomographies taken after 3 days or later. Of 26 patients in stage $B$ initially, 14 (53.8\%) remained as stage B, 8 (30.8\%) regressed to stage $A$ and 4 (15.4\%) patients 
Table 2. Evaluation of the changes in CT scan performed on the 3th-7th day compared to the one performed within the first 12 hours in elderly patients

\begin{tabular}{|l|l|l|l|l|l|l|}
\hline \multirow{2}{*}{$\begin{array}{l}\text { CT: After } \\
\text { 72 hours }\end{array}$} & \multicolumn{7}{|c|}{ CT: On admission } \\
\cline { 2 - 8 } & Stage A & Stage B & Stage C & Stage D & Stage E & Total \\
\cline { 2 - 8 } & $\mathrm{n}(\%)$ & $\mathrm{n}(\%)$ & $\mathrm{n}(\%)$ & $\mathrm{n}(\%)$ & $\mathrm{n}(\%)$ & $\mathrm{n}(\%)$ \\
\hline Stage A & $8(66.6 \%)$ & $0(0 \%)$ & $7(9.7 \%)$ & $3(21.4 \%)$ & $1(5.3 \%)$ & $19(14.7 \%)$ \\
\hline Stage B & $2(16.7 \%)$ & $8(66.7 \%)$ & $4(5.6 \%)$ & $1(7.2 \%)$ & $0(0 \%)$ & $15(11.6 \%)$ \\
\hline Stage C & $2(16.7 \%)$ & $4(33.3 \%)$ & $43(59.7 \%)$ & $3(21.4 \%)$ & $0(0 \%)$ & $52(40.3 \%)$ \\
\hline Stage D & $0(0 \%)$ & $0(0 \%)$ & $10(13.9 \%)$ & $2(14.3 \%)$ & $1(5.3 \%)$ & $13(101 \%)$ \\
\hline Stage E & $0(0 \%)$ & $0(0 \%)$ & $8(11.1 \%)$ & $5(35.7 \%)$ & $17(89.4 \%)$ & $30(23.3 \%)$ \\
\hline Total & $12(100 \%)$ & $12(100 \%)$ & $72(100 \%)$ & $14(100 \%)$ & $19(100 \%)$ & $129(100 \%)$ \\
\hline
\end{tabular}

progressed to stage $\mathrm{C}$. In stage $\mathrm{C}$, there were 79 patients initially, of these 50 (63.3\%) remained as stage C, 23 (29.1\%) regressed to stage $A$ and $B$, and $6(7.6 \%)$ patients progressed to stage $D$ and E. Of 31 patients in stage $D, 11$ (35.5\%) remained as stage $D, 15(48.4 \%)$ regressed to stage $A, B, C$, and $5(16.1 \%)$ patients progressed to stage $E .39$ patients were in stage $\mathrm{E}$ on inital exam. Of these, $29(74.4 \%)$ remained as stage $E$, and $10(26.4 \%)$ patients regressed to stage $A$ to $D$ (Table 3 ).

\section{DISCUSSION}

Although AP shows a mild clinical course in the majority of patients, it is a severe and lifethreatening disease of elderly patients $(15,16,19)$. In recent years, a marked increase in AP-related morbidity has been observed in elderly patients (20). According to a study published in 2017 by Robert et al., which summarizes the results of the European studies, it was observed that the disease progresses more aggressively and has a significant increase in morbidity in individuals over 65 years of age (20).

Various scoring systems are available to assess AP severity. While clinical and laboratory data are used to assess Ranson, APACHE II, and Atlanta scores, Balthazar scoring is based on radiological findings $(9,21)$. Although age is used as a criterion in many scoring systems, there are rare studies examining the relationship between age and Balthazar scoring system (22-25). Moreover, inconsistency between the results of the studies conducted draws attention. Study performed by Losurdo et al. evaluating patients over 70 years of age with acute biliary pancreatitis, showed, older patients despite their high comorbidities had similar clinical severity and mortality with younger patients (14). Vatansever and colleagues found no difference according to the Balthazar scoring and CT severity index in patients with acute biliary pancreatitis among groups aged under 65 and over (22). However, in contrast to this; in another study investigating the relationship between age and the course of the disease, it was reported that the disease showed significantly worse progression in patients over 70 years of age compared to patients under 60 years of age (19). Similarly, Koziel and collegues ported that the course of the disease was more severe in patients with AP over the age of 80 compared to patients under 65 (23). In our study, comparing AP severity in geriatric and non-geriatric groups; 
Table 3. Evaluation of the changes in CT scan performed on the 3th-7th day compared to the one performed within the first 12 hours in non-elderly patients

\begin{tabular}{|l|l|l|l|l|l|l|}
\hline \multirow{2}{*}{$\begin{array}{c}\text { CT: After } \\
72 \text { hours }\end{array}$} & \multicolumn{7}{|c|}{ CT: On admission } \\
\cline { 2 - 8 } & Stage A & Stage B & Stage C & Stage D & Stage E & Total \\
\cline { 2 - 8 } & $\mathrm{n}(\%)$ & $\mathrm{n}(\%)$ & $\mathrm{n}(\%)$ & $\mathrm{n}(\%)$ & $\mathrm{n}(\%)$ & $\mathrm{n}(\%)$ \\
\hline Stage A & $40(80 \%)$ & $8(30.8 \%)$ & $17(21.5 \%)$ & $8(25.8 \%)$ & $2(5,1 \%)$ & $75(33.3 \%)$ \\
\hline Stage B & $2(4 \%)$ & $14(53.8 \%)$ & $6(7.6 \%)$ & $0(0 \%)$ & $1(2.6 \%)$ & $23(10.2 \%)$ \\
\hline Stage C & $6(12 \%)$ & $4(15.4 \%)$ & $50(63.3 \%)$ & $7(22.6 \%)$ & $5(12.8 \%)$ & $72(32.0 \%)$ \\
\hline Stage D & $2(4 \%)$ & $0(0 \%)$ & $4(5.1 \%)$ & $11(35.5 \%)$ & $2(5,1 \%)$ & $19(8.4 \%)$ \\
\hline Stage E & $0(0 \%)$ & $0(0 \%)$ & $2(2.5 \%)$ & $5(16.1 \%)$ & $29(74.4 \%)$ & $36(16 \%)$ \\
\hline Total & $50(100 \%)$ & $26(100 \%)$ & $79(100 \%)$ & $31(100 \%)$ & $39(100 \%)$ & $225(100 \%)$ \\
\hline
\end{tabular}

there was no statistically significant difference between the two groups on admission. Even if CT is considered the gold standard for the diagnosis of pancreatic necrosis, since not all pancreatic necrosis may develop within the first 48 hours, early screening is limited to predict severity (24). In this context, control CT scans were taken after the third day, which demonstrated that severe AP was significantly more common in the elderly group. In addition, comparing the course of the disease (regression, progression or no-change) on initial and control CT scans; geriatric group showed a significantly higher rate of disease progression.

Older patients are known to be more prone to infections in surgical procedures and are associated with a high inflammatory response. Old age is followed by an inflammatory process, which may worsen during certain conditions (sepsis, surgery, ischaemic/reperfusion injury) (25). This condition is associated with antigenic stress, which can lead to lifetime depletion of immunological cells, thus reducing the capacity of the immunological system to respond to antigens $(23,25)$. The aged cells remain metabolically active and produce a number of tumor suppressors and proinflammatory substances. It is also known that older patients are more susceptible to infections after surgical procedures, and this may be related to the patients ' proinflammatory status. This increased susceptibility to infections contributes to increased postoperative morbidity and mortality in older patients $(24,26)$. Older patients often seek late medical attention. They experience anxiety about becoming adependent person, about the possibility of inadequate care provided by relatives, or fear of a simple hospitalization or impending death (26). In addition, the presence of accompanying chronic diseases in these patients negatively affects the already decreased physiological functions of geriatric patients. This results in a severe reduction of physiological reserve to deal with an inflammatory condition, leading to a more serious AP clinical symptom (11). Some researchers have associated increased mortality in the elderly with higher mortality rates due to accompanying medical or surgical diseases, not complications directly from $\operatorname{AP}(25,26)$. The rates of mortality are high in severe AP due to multiorgan dysfunction and it is still about $20-25 \%$ $(27,28)$. Despite age is generally accepted as a risk factor for multisystem organ failure, there are controversial data about increased mortality from AP in elderly patients $(27,28)$. In a study by Uomo et 
al., mortality was shown to be significantly higher among the patients aged over 70 years $(25.8 \%$ vs $7.8 \%$ ) (29). In another study with 884 patients, mortality was found to be significantly increased in elderly patients (7.4\% vs $1.9 \%$ ) (30). In the our study, we showed that mortality was significantly increased in the elderly population (3.1\% vs $0.4 \%$ ).

This study has some limitations. It is a single center retrospective study and other risk factors that play a role in disease progression are not discussed in detail. The strengths of our study are the high number of patients included and the fact that both tomographies ( initial and control after 3rd day) have been evaluated by the same radiologist, permitting a reliable comparision of disease severity and its course.

\section{REFERENCES}

1. Lankisch PG, Apte M, Banks PA. Acute pancreatitis. Lancet 2015;386:85-96 (PMID: 25616312).

2. Singla A, Simons J, Li Y, et al. Admission volume determines outcome for patients with acute pancreatitis. Gastroenterology 2009;137: 1995-2001. (PMID: 19733570).

3. Tozlu M, Kayar $Y$, Ince AT, Baysal B, Senturk H. Low molecular weight heparin treatment of acute moderate and severe pancreatitis: A randomized, controlled, open-label study. Turk J Gastroenterol 2019 Jan;30(1):81-7. (PMID: 30289392).

4. Abu-Zidan FM, Bonham MJ, Windsor JA. Severity of acutepancreatitis: a multivariate analysis of oxidative stress markers and modified Glasgow criteria. $\mathrm{Br} \mathrm{J}$ Surg 2000;87:1019-23. (PMID: 10931044).

5. Goldacre MJ, Roberts SE. Hospital admission for acute pancreatitis in an English population, 196398: data base study of incidence and mortality. BMJ 2004;328:1466-9. (PMID: 15205290).

6. Kayar Y, Senturk H, Tozlu M, Baysal B, Atay M, Ince AT. Prediction of Self-Limited Acute Pancreatitis Cases at Admission to Emergency Unit.GE Port J Gastroenterol 2019 Jul;26(4):251-9. (PMID: 31328139).

7. Gardner T.B, Santhi Swaroop V, Suresh S.T, et al. The effect of age on hospital outcomes in severe acute pancreatitis. Pancreatology 2008;8:265-70. (PMID: 18497539).

8. Blamey S.L, Imrie CW, O'Neill J, Gilmour WH, Carter
In conclusion, although in our study there was no statistically significant difference between geriatric and non-geriatric groups in terms of severity of AP according to modified Balthazar classification on initial CT scans, severe AP was significantly more common in patients aged 65 years or older on control tomographies taken after the third day. In $A P$, age can affect the severity of the disease. Different therapeutic strategies are recommended for young and old patients to control AP. Based on the findings of this study, AP treatment in elderly patients should be substantially comprehensive. The effect of age on the clinical outcomes in patients with acute pancreatitis is not yet clear and detailed prospective studies are needed.

DC. Prognostic factors in acute pancreatitis. Gut 1984;25:1340-6. (PMID: 6510766).

9. Ranson JHC, K M Rifkind, D F Roses, S D Fink, K Eng, F C Spencer. Prognostic signs and the role of operative management in acute pancreatitis. Surg Gynecol Obstet 1974;139:69-81. (PMID: 4834279).

10. Wilson C, Heath D.I, Imrie C.W. Prediction of outcome in acute pancreatitis: a comparative study of APACHE II, clinical assessment and multiple factor scoring systems. Br. J. Surg 1990;77:1260-4. (PMID: 2253005).

11. Nguyen BL, Thompson JS, Edney JA. Influence of the etiology of pancreatitis on the natural history of pancreatic pseudocysts. Am J Surg 1991;162:527530. (PMID: 1670219).

12. Gullo L, Migliori M, Olah A, et al. Acute pancreatitis in five European countries. Etiol Mortality Pancreas 2002;24:223-7. (PMID: 11893928).

13. Roulin D, Girardet R, Duran R, et al. Outcome of elderly patients afte acute biliary pancreatitis. Biosci Trends 2018;12:54-9. (PMID: 29553102).

14. Losurdo G, lannone A, Principi M, Barone M et al. Acute pancreatitis in elderly patients: A retrospective evaluation at hospital admission. Eur J Intern Med 2016;30:88-93. (PMID: 26806437).

15. De Beaux A.C, Palmer K.R, Carter D.C, Factors influencing morbidity and mortality in acute pancreatitis: an analysis of 279 cases. Gut 1995;37:121- 
6. (PMID: 7672660).

16. Tenner S, Baillie J, DeWitt J, Vege SS. American College of Gastroenterology. American College of Gastroenterology guideline: management of acute pancreatitis. Am J Gastroenterol 2013;108:1400-16. (PMID: 23896955).

17. Charlson ME, Pompei P, Ales KL, MacKenzie CR. A new method of classifying prognostic comorbidity in longitudinal studies: development and validation. J Chronic Dis 1987; 40(5): 373-83. (3558716).

18. Balthazar EJ, Freeny PC, Van-Sonnenberg E. Imaging and intervention in acute pancreatitis. Radiology 1994;193:297-306. (PMID: 7972730).

19. McKay C.J, Evans S, Sinclair M, Imrie CW. High early mortality rate from acute pancreatitis in Scotland, 1984-1995. Br. J. Surg 1999;86:1302-5. (PMID: 10540138).

20. Roberts SE, Morrison-Rees S, John A, Williams JG, Brown TH, Samuel DG. The incidence and a etiology of acute pancreatitis across Europe. Pancreatology 2017;17(2):155-65. (PMID: 28159463).

21. Balthazar EJ, Robinson DL, Megibow AJ, Ranson $\mathrm{JH}$. Acute pancreatitis: value of $\mathrm{CT}$ in establishing prognosis. Radiology 1990;174:331-6. (PMID: 2296641).

22. Vatansever S, Doğru R, Pakoz Z. Genc H, Unal B. Evaluation of Laboratory Findings and Mortality in Elderly Patients with Acute Biliary Pancreatitis. Med Bull Sisli Etfal Hosp 2018;52(4):274-8. (DOI: 10.14744/ SEMB.2018.37791).

23. Koziel D, Gluszek-Osuch M, Suliga E, Zak M, Gluszek
S. Elderly persons with acute pancreatitis-specifics of the clinical course of the disease. Clin Interv Aging 2019;14:33. (PMID: 30613137).

24. Ryu J.K. Evaluation of severity in acute pancreatitis. Korean J Gastroenterol 2009;54:205-11.( PMID: 19844139).

25. Cevenini E, Caruso C, Candore G, et al. Age-related inflammation: the contribution of different organs, tissues and systems. How to face it for therapeutic approaches. Curr Pharm Des 2010;16(6):609-18. (PMID: 20388071).

26. Lyon C, Clark DC. Diagnosis of acute abdominal pain in older patients. Am Fam Physician 2006;74(9):153744. (PMID: 17111893).

27. Frossard JL, Steer ML, Pastor CM. Acute pancreatitis. Lancet 2008; 371: 143-52. (PMID: 18191686).

28. Malangoni MA, Martin AS. Outcome of severe acute pancreatitis. Am J Surg 2005; 189: 273-7. (PMID: 15792749).

29. Uomo G, Talamini G, Rabitti P, Cataldi F, Cavallera $A$, Rengo F. Influence of advanced age and related comorbidity on the course and outcome of acute pancreatitis. Ital J Gastroenterol Hepatol 1998; 30: 616-21. (PMID: 10076785).

30. Quero G, Covino M, Fiorillo C, Rosa F, Menghi R, Simeoni B, Potenza A, Ojetti V, Alfieri S, Franceschi F. Acute pancreatitis in elderly patients: a singlecenter retrospective evaluation of clinical outcomes. Scand J Gastroenterol 2019 Apr; 54(4): 492-8. (PMID: 30905212). 